\title{
From field experiments to salinity products: a tribute to the contributions of Jordi Font to the SMOS mission
}

\author{
Adriano Camps 1,2,3, Carolina Gabarró ${ }^{3,4}$, Mercè Vall-llossera ${ }^{1,2,3}$, Sebastià Blanch ${ }^{1}$, \\ Albert Aguasca ${ }^{1}$, Francesc Torres ${ }^{1,3}$, Ignasi Corbella ${ }^{1,3}$, Nuria Duffo ${ }^{1,3}$, Antonio Turiel ${ }^{3,5}$, \\ Marcos Portabella ${ }^{3,4}$, Joaquim Ballabrera-Poy 3,4, Verónica González-Gambau ${ }^{3,4}$, \\ Justino Martínez ${ }^{3,4}$, Ramón Villarino ${ }^{5}$, Luís Enrique ${ }^{6}$, Alessandra Monerris ${ }^{7}$, Xavier Bosch ${ }^{8}$, \\ Roberto Sabia ${ }^{9}$, Marco Talone ${ }^{10}$, Maria Piles ${ }^{1,2,3}$, Míriam Pablos ${ }^{1,2,3}$, Enric Valencia ${ }^{1}$ \\ ${ }^{1}$ Dept. Teoria del Senyal i Comunicacions, Universitat Politècnica de Catalunya, c/ Jordi Girona 1-3, Campus Nord, 08034 \\ Barcelona, Spain. \\ ${ }^{2}$ IEEC/CTE-UPC, C/ Gran Capità, 2-4, desp 201, 08034 Barcelona, Spain. \\ ${ }^{3}$ SMOS Barcelona Expert Centre, CSIC-UPC, Pg. Marítim Barceloneta 37-49, 08003 Barcelona, Spain. \\ ${ }^{4}$ Institut de Ciències del Mar, CSIC, Pg. Marítim Barceloneta 37-49, 08003 Barcelona, Spain. \\ ${ }^{5}$ Dept. d'Eng. Electrònica, Elèctrica i Automàtica, Universitat Rovira i Virgili, Av. Països Catalans, 26, \\ 43007 Tarragona, Spain. \\ ${ }^{6}$ ICFO, Mediterranean Technology Park, Av. Carl Friedrich Gauss, 3, 08860 Castelldefels, Barcelona, Spain. \\ ${ }^{7}$ Faculty of Engineering, Monash University, Clayton Campus, Victoria 3168, Australia. \\ ${ }^{8}$ Microwave Systems Lab., Dept. of Electrical and Computer Eng., Colorado State Univ., Fort Collins, CO 80523 USA. \\ ${ }^{9}$ Telespazio-Vega UK Ltd for ESA/ESRIN, Via Galileo Galilei, Casella Postale 64, 00044 Frascati (Roma), Italy. \\ ${ }^{10}$ Institute for Environment and Sustainability (IES), EC Joint Research Centre, via Enrico Fermi, 2749, Ispra, Italy.
}

\begin{abstract}
Summary: This article summarizes some of the activities in which Jordi Font, research professor and head of the Department of Physical and Technological Oceanography, Institut de Ciències del Mar (CSIC, Spanish National Research Council) in Barcelona, has been involved as co-Principal Investigator for Ocean Salinity of the European Space Agency Soil Moisture and Ocean Salinity (SMOS) Earth Explorer Mission from the perspective of the Remote Sensing Lab at the Universitat Politècnica de Catalunya. We have probably left out some of his many contributions to salinity remote sensing, but we hope that this review will give an idea of the importance of his work. We focus on the following issues: 1) the new accurate measurements of the sea water dielectric constant, 2) the WISE and EuroSTARRS field experiments that helped to define the geophysical model function relating brightness temperature to sea state, 3) the FROG 2003 field experiment that helped to understand the emission of sea foam, 4) GNSS-R techniques for improving sea surface salinity retrieval, 5) instrument characterization campaigns, and 6) the operational implementation of the Processing Centre of Levels 3 and 4 at the SMOS Barcelona Expert Centre.
\end{abstract}

Keywords: SMOS; radiometry; interferometry; calibration; validation; salinity; soil moisture; sea ice; GNSS-R.

De campañas de medidas a productos de salinidad: un tributo a las contribuciones de Jordi Font a la mision SMOS

Resumen: Este artículo resume algunas de las actividades en las que Jordi Font, profesor de investigación y jefe del Departamento de Física y Tecnología Oceanográfica, del Institut de Ciències del Mar (CSIC) en Barcelona, ha estado desarrollando como co-Investigador Principal de la parte de la misión SMOS de la ESA, una misión Earth Explorer, desde la perspectiva del Remote Sensing Lab, de la Universitat Politècnica de Catalunya. Seguramente, estamos olvidando algunas de sus muchas contribuciones a la teledetección de la salinidad, pero esperamos que esta revisión dé una idea de la importancia de su trabajo. Este artículo se focaliza en los siguientes puntos: 1) las medidas de alta calidad de la constante dieléctrica del agua marina, 2) las campañas de medidas WISE y EuroSTARRS que ayudaron a la definición del modelo geofísico relacionando la temperatura de brillo con el estado del mar, 3) la campaña de medidas FROG 2003 que ayudó a entender la emisión de la espuma marina 4) presentación de las técnicas de GNSS-R para la mejora de la recuperación de la salinidad superficial 5) campañas para la caracterización del instrumento y 6) la implantación del centro de procesado operacional de niveles 3 y 4 en el SMOS Barcelona Expert Centre.

Palabras clave: SMOS; radiometría; interferometría; calibración; validación; salinidad; humedad del terreno; hielo marino; GNSS-R.

Citation/Como citar este artículo: Camps A., Gabarró C., Vall-llossera M., Blanch S., Aguasca A., Torres F., Corbella I., Duffo N., Turiel A., Portabella M., Ballabrera-Poy J., González-Gambau V., Martínez J., Villarino R., Enrique L., Monerris A., Bosch X., Sabia R., Talone M., Piles M., Pablos M., Valencia E. 2016. From field experiments to salinity products: a tribute to the contributions of Jordi Font to the SMOS mission. Sci. Mar. 80S1: 159-172. doi: http://dx.doi.org/10.3989/ scimar.04285.04A 
Editor: J.L. Pelegrí.

Received: June 9, 2015. Accepted: December 10, 2015. Published: September 30, 2016.

Copyright: () 2016 CSIC. This is an open-access article distributed under the terms of the Creative Commons Attribution (CC-by) Spain 3.0 License.

\section{INTRODUCTION}

The Remote Sensing Laboratory of the Department of Signal Theory and Communications at the Universitat Politècnica de Catalunya - BarcelonaTech, has been involved since 1993 in the technological aspects of the Microwave Imaging Radiometer with Aperture Synthesis (MIRAS), the single payload of the European Space Agency Soil Moisture and Ocean Salinity (SMOS) Earth Explorer Opportunity mission. We first met Professor Jordi Font in 1998, during the preparation of what later became the SMOS Mission. Since then, we have enjoyed a fruitful scientific collaboration, which has also led to a longstanding friendship. This paper is a tribute to Professor Font's achievements in remote sensing of the ocean over the last 17 years.

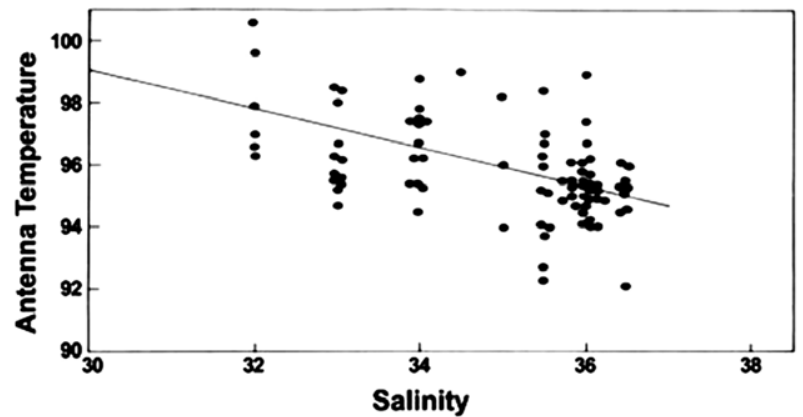

Fig. 1. - Antenna Temperature and Salinity Correlation in Skylab Data (http://aquarius.umaine.edu/images/ov_skylab_data.jpg)

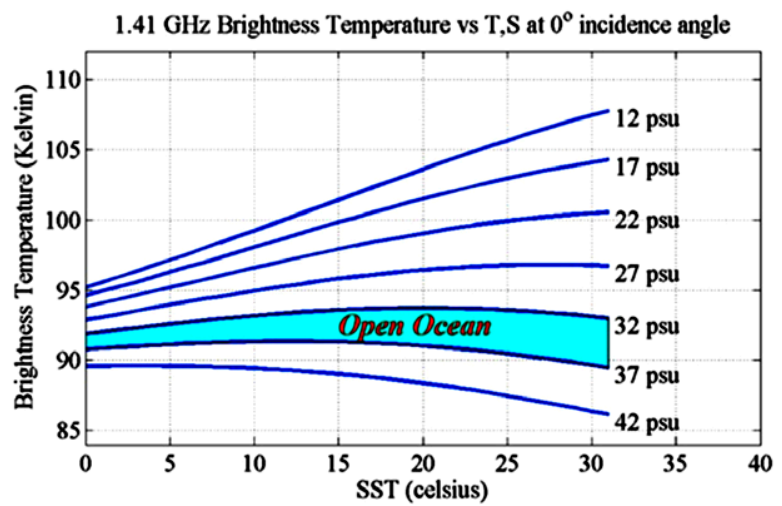

Fig. 2. - Brightness temperature at nadir dependence with sea surface temperature (SST) and sea surface salinity (SSS) (Swift 1980).

Sea surface salinity (SSS) can be remotely measured using microwave radiometry at L-band (Swift et al. 1983). During the late 1940 s and early 1950 s, laboratory experiments were conducted to quantify the relationship between salinity and brightness temperature. Until SMOS, only two (experimental) space-borne radiometers at L-band had been launched, in Cosmos 243 (1968) and in Skylab S-194 (1973), but the first evidence from space came only from the Skylab observations (Fig. 1).

The link between salinity and brightness temperature is through the dielectric constant of sea water. Though the "protected" 1.400-1.427 MHz band is the best choice, these measurements are far from trivial
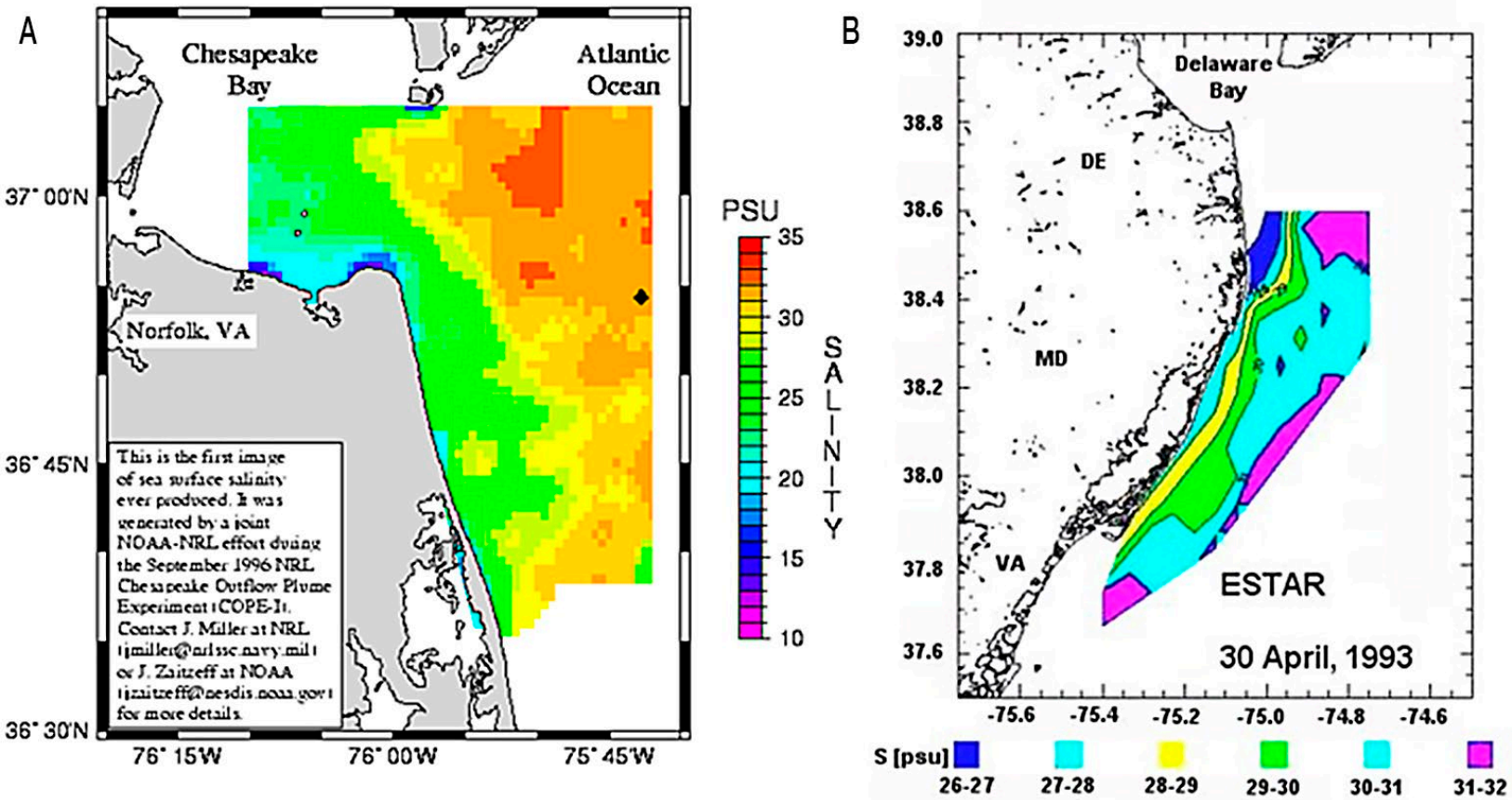

Fig. 3. - A, first sea surface salinity map derived from L-band microwave radiometry in 1996 (Miller et al. 1996); B, first sea surface salinity map derived from a synthetic aperture radiometer in 2000 (LeVine et al. 2000). 

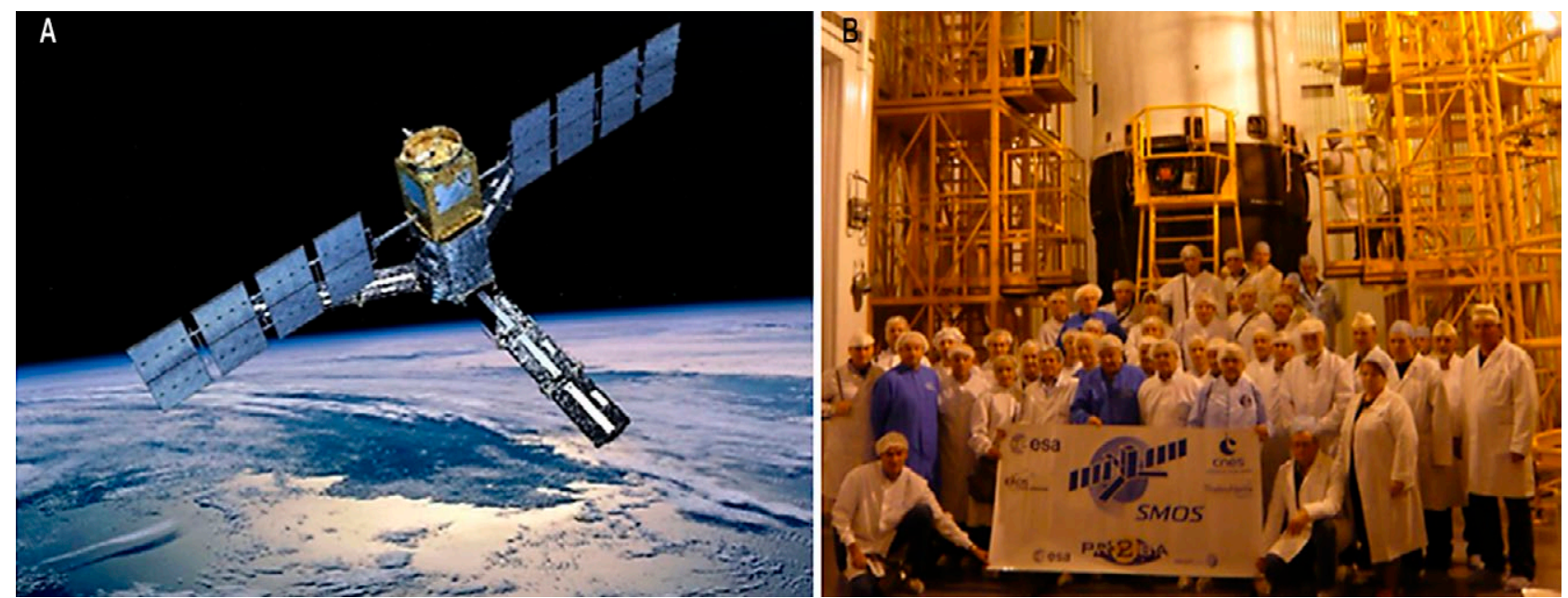

Fig. 4. - A, SMOS artist's view in orbit; B, Jordi Font with the ROCKOT launcher behind with SMOS inside, ready to be launched at Plesetsk, Russia.

due to the low sensitivity of brightness temperature to $\mathrm{SSS}, 0.2-0.8 \mathrm{~K} / \mathrm{psu}$ (psu = practical salinity unit, roughly $1 \mathrm{~g}$ of salt per $1 \mathrm{~kg}$ of water), the dependence on the physical temperature (Fig. 2), incidence angle, polarization, surface roughness (induced by local wind or by far waves), the technical difficulties of achieving a precise calibration and stability, and especially the presence of radio-frequency interference (RFI).

The first SSS airborne map was published in 1996 by Miller and Zaitzeff (Miller et al. 1996) using the scanning low frequency microwave radiometer (SLFMR), a six-beam real aperture radiometer (Fig. 3A). In 2000, LeVine et al. obtained an SSS map using the electronically steered thinned array radiometer (ESTAR), the first in-orbit $1 \mathrm{D}$ synthetic aperture radiometer (LeVine et al. 2000) (Fig. 3B).

In 1995, the ESA organized the Soil Moisture and Ocean Salinity Workshop to define the roadmap to remotely measure these two geophysical variables, and it was concluded that the most promising technique was aperture synthesis radiometry, which had been successfully demonstrated a few years earlier with the ESTAR instrument (Ruf et al. 1998). In 1998, an international team of scientists proposed the SMOS mission to ESA. It was selected as the second Earth Explorer
Opportunity Mission (Silvestrin et al. 2001) within the ESA Living Planet Programme and was launched on 2 November 2009 from Plesetsk, Russia (Figs 4 and 5).

\section{TOWARDS A BETTER UNDERSTANDING OF SEA SURFACE EMISSION}

In 1998, when the SMOS proposal was submitted, as in any mission, there were many uncertainties and many lessons to be learnt. For ocean salinity retrieval, three key goals related to the geophysical model function had to be met:

- to more accurately characterize the impact of salinity and temperature on the dielectric constant,

- to account for the impact of the sea state (wind speed, significant wave height, etc.) on the brightness temperatures, and

- to account for the impact of sea foam on the brightness temperatures.

\section{Towards a more accurate determination of the sea water dielectric constant}

Two of the most widely used dielectric constant models are those of Klein and Swift (1977) and Ellison
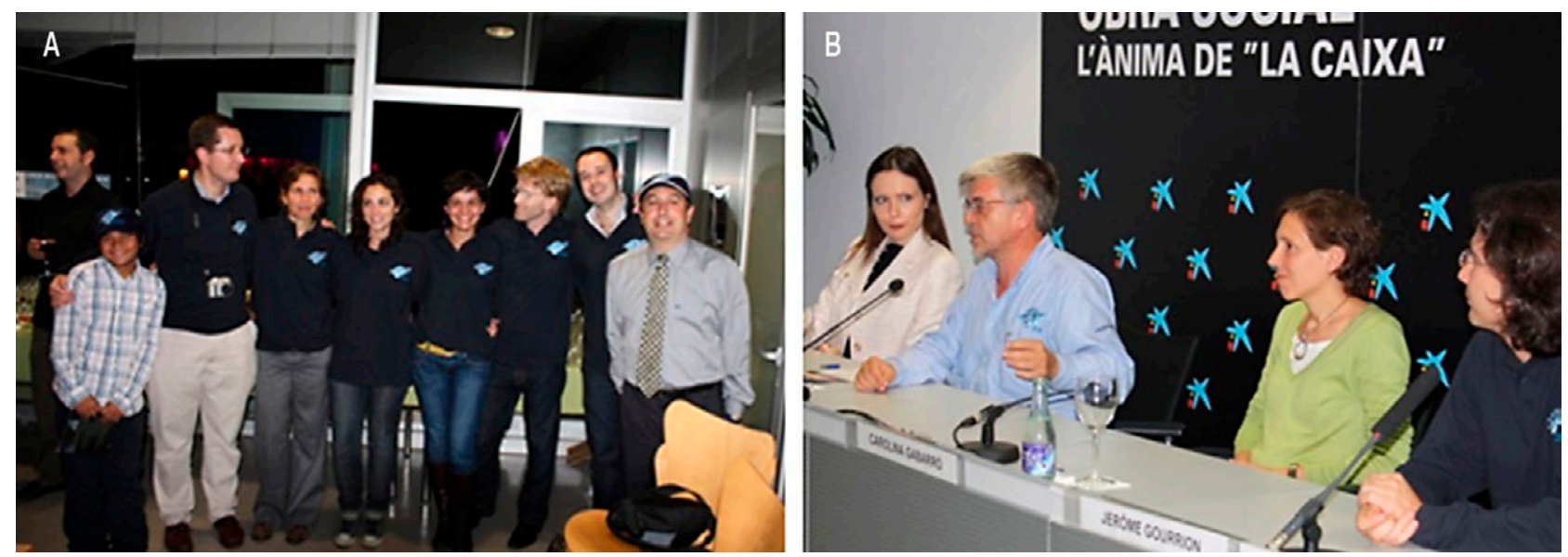

Fig. 5. - A, the BEC team during the SMOS launch at the ICM; B, media press conference after the launch. 

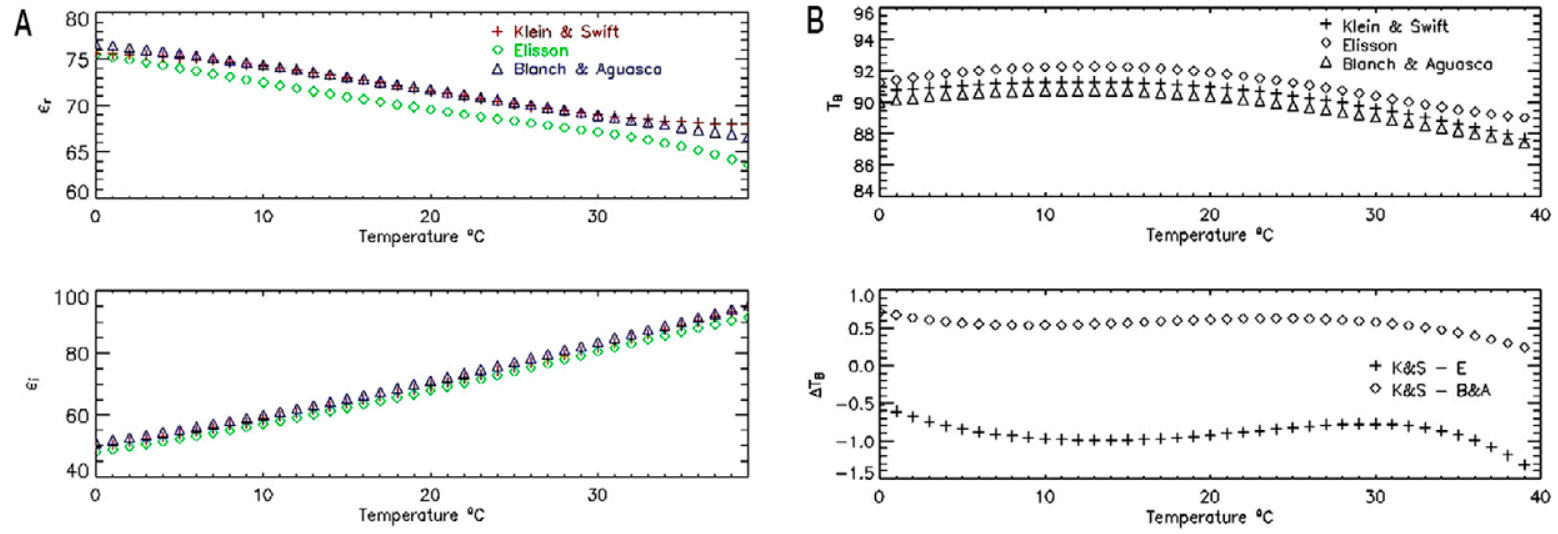

Fig. 6. - Comparison between the Klein and Swift, Ellison and Blanch and Aguasca dielectric constant models. A, real and imaginary part of the dielectric constant; B, brightness temperature at nadir for $37.5 \mathrm{psu}$ as a function of the temperature (Gabarró 2004).

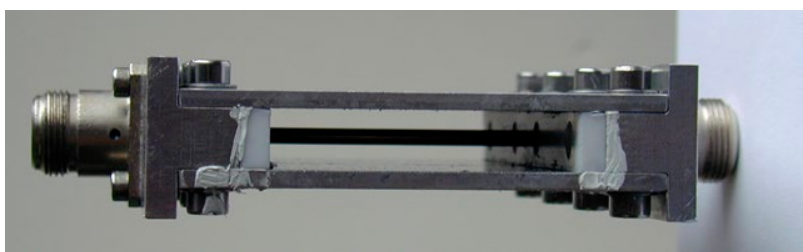

Fig. 7. - Measurement device.

et al. (1998). Although they show similar results (see Fig. 6), their differences are too great to meet the accuracy requirements, i.e. for an absolute accuracy of $0.2 \mathrm{psu}$, the brightness temperature must be in the order of $0.1 \mathrm{~K}$ for cold waters (Fig. 2).

Most of the methods used to determine the dielectric constant are based on reflectivity measurements in a transmission line, such as the open-ended coaxial sensor. However, these methods require well-known calibrators and they are not accurate enough for this application. Other techniques based on the change in the resonant properties of a cavity are very accurate but provide more limited information (single frequency, temperature and salinity). Finally, transmission methods provide accurate and more comprehensive information from the measurement of the propagation changes of the electromagnetic signal (S-parameters measured with a vector network analyser). This was the technique selected in Blanch and Aguasca (2004) to derive the dielectric constant of sea water. The test device is shown in Figure 7. It consists of a metallic waveguide through which temperature controlled salty water can circulate by means of a pump. The dimensions were calculated so that a single mode propagates even when the device is filled with salt water.

The main results are summarized in Figure 6 . The Klein and Swift (KS) and Blanch and Aguasca (BA) models show similar dielectric constant results for medium temperatures, whereas the Ellison model is slightly different, especially in the real part of the permittivity. Also, the KS and BA models give similar results on brightness temperature, while the Ellison model tends to overestimate it. However, it is difficult to ensure absolute accuracy because of the lack of absolute references.

\section{Towards a better understanding of the impact of sea state}

Since 1971, no systematic measurements had been performed to assess the impact of the sea state (parameterized in terms of the wind speed, the significant wave height or other descriptors). Additionally, only a few airborne experiments had been carried out, mostly with the SLFMR real aperture radiometer (Miller et al.
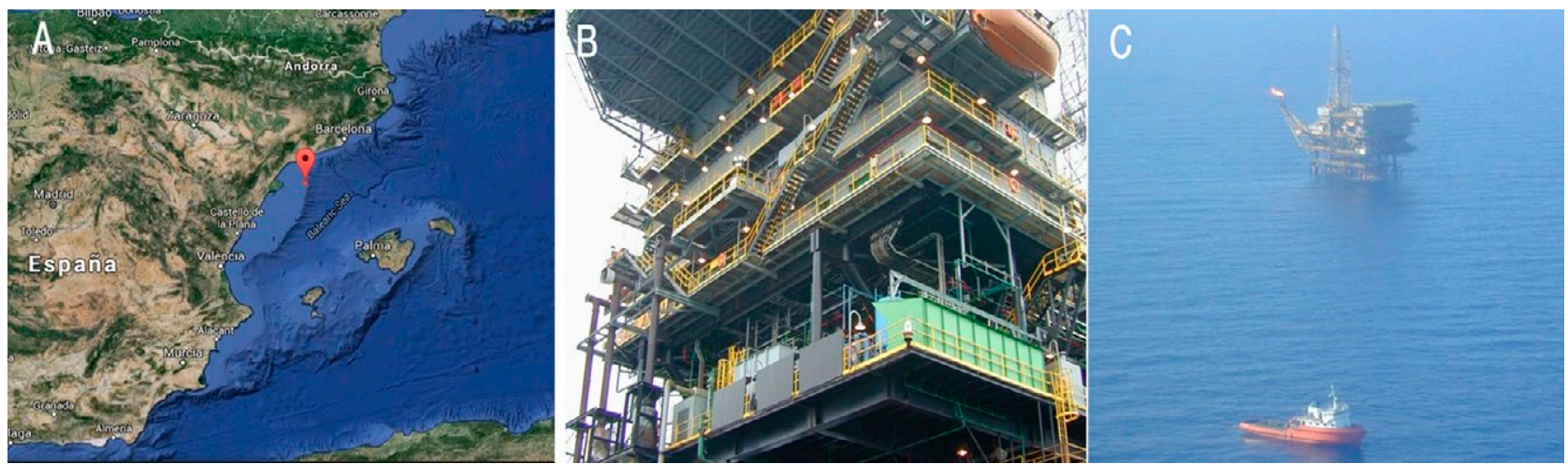

Fig. 8. - A, location of the REPSOL Casablanca oil rig in the Mediterranean coast of Catalonia; B, image of the north side showing the location of the instruments; $\mathrm{C}$, heavy equipment was transported to Casablanca oil rig by ship, while delicate goods and personnel were flown by helicopter. 

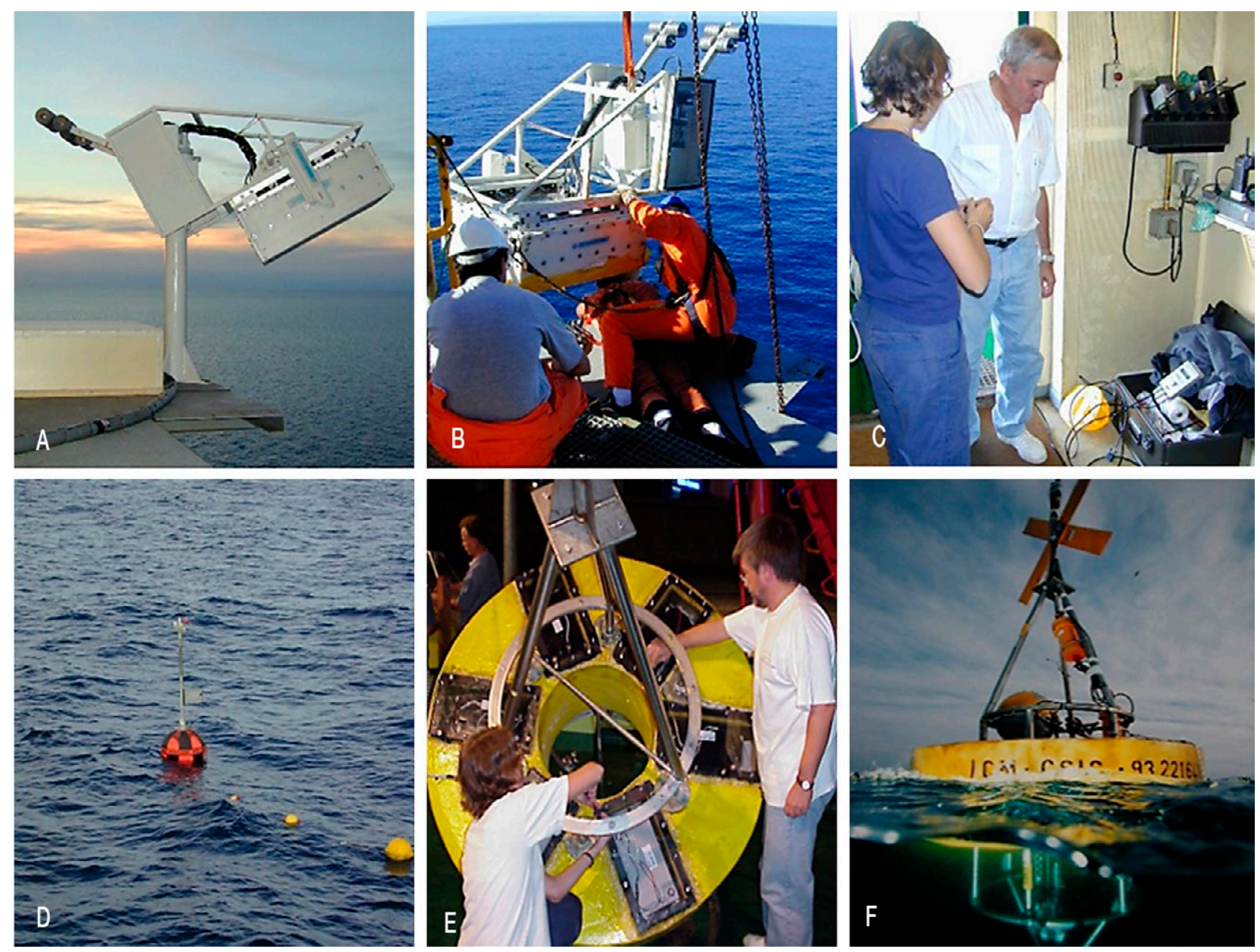

Fig. 9. - Some instrumentation deployed during WISE 2000 and 2001: A, LAURA installed and acquiring data from the $32 \mathrm{~m}$ height deck; B, LAURA (L-band AUtomatic polarimetric Radiometer) during installation (UPC); C, Carolina Gabarró and Agustí Julià checking the radio link with the Aanderaa buoy; D, Aanderaa CMB3280 (meteorological buoy, ICM/CSIC); E, Prof. Font preparing the buoy designed at ICM with the CT recorder to sample near-surface salinity; F, underwater view of the buoy.

1996, Hollinger 1971), and one with the ESTAR synthetic aperture radiometer (LeVine et al. 2000).

In 1999 we proposed to ESA the possibility to carry out the WInd and Salinity Experiment (WISE) on the REPSOL Casablanca oil rig $\left(40.72^{\circ} \mathrm{N} 1.36^{\circ} \mathrm{E}\right), \sim 50 \mathrm{~km}$ offshore of the coast of Tarragona (Spain), and 115 $\mathrm{km}$ south of Barcelona (see Fig. 8). Two WISE campaigns took place (November 2000 to January 2001) and October to November 2001), and were the result of teamwork by the Universitat Politècnica de Catalunya (Barcelona, Spain), the Institut de Ciències del Mar/ CSIC (Barcelona, Spain), the Universitat de València (València, Spain), LODYC (later LOCEAN, Paris, France), the Centre d'Etudes des Environnements Terrestre et Planétaires (CETP, later LATMOS, Vélizy, France), and in 2000 the Microwave Remote Sensing Laboratory of the University of Massachusetts (Ahmerst, USA).

The instruments deployed were (Fig. 9): LAURA (L-band AUtomatic RAdiometer), the first ever fully polarimetric (4 Stokes elements) L-band radiometer (UPC), a Ka-band polarimetric radiometer (UMass), a stereo-camera to determine surface topography and root mean square slopes of the sea surface (CETP), four oceanographic and climatological buoys for nearsurface salinity, temperature, wind speed and direction, wave height and period, etc. (ICM-CSIC and LODYC), a portable meteorological station with atmospheric pressure, air temperature, relative humidity and rain rate (UPC), a video camera mounted on the L-band radiometer pedestal to determine sea surface foam coverage (UPC), and an IR radiometer to determine sea surface temperature estimates (UV). Additionally, during WISE 2000, temperature and salinity were recorded from the platform at $5 \mathrm{~m}$ below sea level, and simultaneously ocean colour, wind vector and sea surface temperature were acquired by different satellites.

Professor Font and Agustí Julià designed an ad hoc buoy for WISE 2000, to collect conductivity and temperature data near the sea surface close to the radiometer field of view and send them to a data logging station installed on the platform using a real-time link (Figs 9E and 9F). The buoy was built by EMS Environmental Monitoring Systems S.L. and modified for WISE 2001 mainly to host extra power batteries. It was a toroidal body with a stainless steel structure to house the signalization elements (flash, radar reflector and satellite ARGOS beacon) and the measuring and trans- 
mitting instruments. The main instrument was a SeaBird MicroCAT system (model SBE37-SM) used to record water temperature and conductivity for further salinity determination. An RS-232 interface allowed real-time data transmission by an external UHF link. An additional submersible pump was added to ensure a constant water flow through the conductivity cell. The water inlet was situated at $20 \mathrm{~cm}$ below sea level in the central part of the toroid, to minimize the effect of waves that might cause air bubbles to be introduced into the measuring cell. Salinity was computed according to established standards with $0.003 \mathrm{psu} / \mathrm{month}$ stability, and 0.0002 psu resolution. The conductivity cell was equipped with a chemical poison device to avoid biofouling and degradation of the conductivity measurement.

The main accomplishment of the WISE campaigns was probably the determination of the brightness temperature dependence with respect to the $10 \mathrm{~m}$ height wind speed and the significant wave height required to perform the necessary corrections to retrieve SSS (Camps et al. 2002, Camps et al. 2004, Gabarró et al. 2004), including a weak azimuthal signature, which was more clearly seen during a very intense storm that occurred in November 2001:

$$
\begin{gathered}
T_{h} \approx 0.25\left(1+\frac{\theta_{i}}{118^{\circ}}\right) U_{10} ; R=0.79 \\
T_{v} \approx 0.25\left(1+\frac{\theta_{i}}{45^{\circ}}\right) U_{10} ; R=0.90 \\
T_{h} \approx 1.09\left(1+\frac{\theta_{i}}{142^{\circ}}\right) S W H ; R=0.88 \\
T_{v} \approx 0.92\left(1+\frac{\theta_{i}}{51^{\circ}}\right) U_{10} ; R=0.78
\end{gathered}
$$

The processing of the data revealed the following: - A sensitivity to wind speed extrapolated at nadir of $\sim 0.23 \mathrm{~K} /\left(\mathrm{m} \mathrm{s}^{-1}\right)$, or a little bit higher, $\sim 0.25 \mathrm{~K} /\left(\mathrm{m} \mathrm{s}^{-1}\right)$, when the atmospheric instability or only the measurements corresponding to $U_{10}>2 \mathrm{~m} \mathrm{~s}^{-1}$ are accounted for. This sensitivity increases at $\mathrm{H}$-polarization up to $\sim 0.5$ $\mathrm{K} /\left(\mathrm{m} \mathrm{s}^{-1}\right)$ at $65^{\circ}$, and decreases at V-polarization down to $\sim-0.2 \mathrm{~K} /\left(\mathrm{m} \mathrm{s}^{-1}\right)$ at $65^{\circ}$, with a zero-crossing around $50^{\circ}-55^{\circ}$, in agreement with the small slope approximation method using Durden-Vesecky times 2 and Elfouhaily et al. sea spectra. It is very likely that the computed wind speed sensitivities below $2 \mathrm{~m} \mathrm{~s}^{-1}$ are erroneous.

- A modulation of the instantaneous brightness temperatures due to wave slopes (and also foam), which makes the standard deviation of this modulation increase with wind speed at a rate of $\sim 0.1-0.15 \mathrm{~K} /(\mathrm{m}$ $\mathrm{s}^{-1}$ ), depending on polarization, and very weakly on incidence angle.

- A sensitivity to significant wave height extrapolated to nadir of $\sim 1 \mathrm{~K} / \mathrm{m}$, increasing at $\mathrm{H}$-polarization up to $\sim 1.5 \mathrm{~K} / \mathrm{m}$ at $65^{\circ}$, and decreasing at $\mathrm{V}$-polarization down to $-0.5 \mathrm{~K} / \mathrm{m}$ at $65^{\circ}$.

- A small azimuthal modulation of $\sim 0.2-0.3 \mathrm{~K}$ for lowto-moderate wind speeds, in reasonable agreement with the numerical models, but very large (peak-to-peak modulations of 4-5 K) during a strong storm recorded on 10 November 2001 (Fig. 10).

The brightness temperature sensitivity to wind speed and significant wave height compared satisfactorily with numerical models; these sensitivities were used until calibrated SMOS data were available, from which new roughness models were formulated (Gabarró et al. 2004, Guimbard et al. 2012).

EuroSTARRS was an ESA campaign in support of the SMOS mission that took place from 17-24 November 2001, while the WISE 2001 campaign was taking place. The US STARRS (Salinity Temperature and
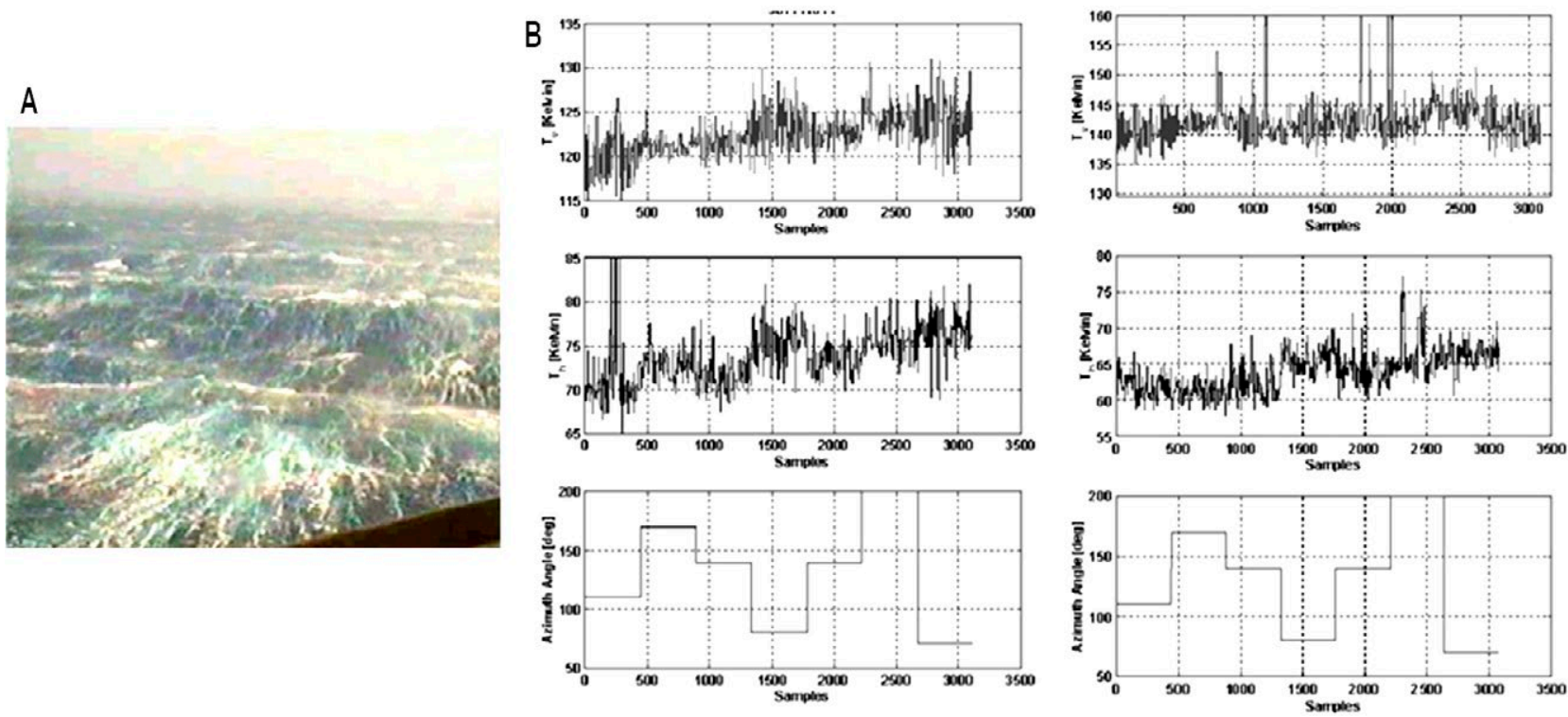

Fig. 10. - A, picture taken from 32-m-high deck of the Casablanca oil rig, waves destroyed the 7-m deck and seriously harmed the 13-m deck; $\mathrm{B}$, vertical polarization (upper row), horizontal polarization (central row), and azimuth angle (bottom row) for two azimuthal scans during the storm (Camps et al. 2004) 

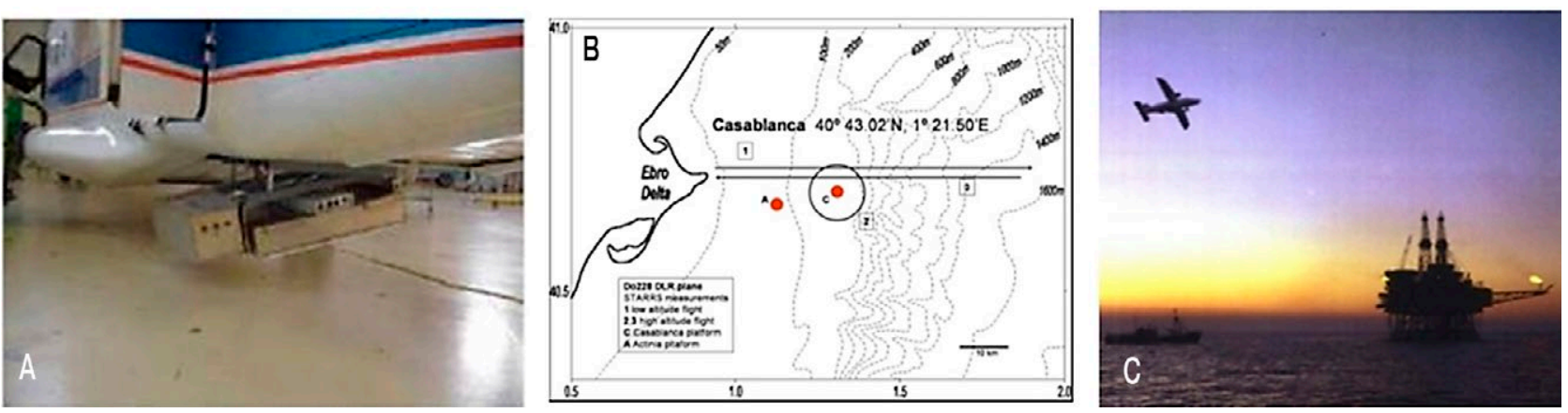

Fig. 11. - A, picture of the STARRS instrument mounted on the plane; B, flight acquisition plan; C, image of the plane flying over the Casablanca oil rig.

Roughness Remote Scanner) L-band radiometer was mounted on a DLR plane and overflew several regions of Europe (see Fig. 11A). The main objective of EuroSTARRS 2001 was to acquire SMOS-like observations to address a range of critical issues relevant to the SMOS mission. Several flights were dedicated to ocean salinity experiments and were coordinated by Jordi Font. The experiment was defined, among other objectives, to allow the data acquired to estimate multiangular L-band microwave signatures from low-altitude flights; to compare data acquired at low altitude with data acquired at high altitude; to investigate emission from urban areas and the level of RFI, to validate ocean salinity retrievals along salinity gradients from the coast out to the sea; and to investigate azimuthal effects on the emission over sea.

One of the sites was around the Casablanca oil rig, near the mouth of the Ebro River (Tarragona), mainly to study the effect of wind speed on the salinity measurements and to investigate azimuth dependence. In the Casablanca area, the flight acquisition plan consisted of three phases (see Fig. 11B, C). The first one was a straight transect from the coast towards the platform, which was selected to avoid interferences from the platform. The second consisted in performing ten circles at a constant bank angle of $22^{\circ}$ to obtain a large range of incidence angles. The last was the reverse course along the first transect flown at low altitude. The measurements were made after sunshine, in order to avoid interference from sun glint.
The Institut de Ciències del Mar (ICM) participated actively during the flight over the Casablanca oil rig on 21 November. Simultaneously to the airborne flight, two types of measurement were made over the area. The CSIC's R/V Garcia del Cid carried out a survey in a rectangular area around the Casablanca rig coincident with the plane overflight, collecting oceanographic data, such as underway near-surface temperature and salinity records, CTD profiles spread across the site, acoustic Doppler current profiles and meteorological measurements on-board in a continuous mode. The results were published (Font et al. 2003, Gabarró et al. 2003, Emelianov 2003).

\section{Understanding the impact of sea foam}

One of the open questions from WISE 2000 and 2001 was the evident modulation of the brightness temperatures when a patch of foam appeared in the antenna beam (e.g. Fig. 10b). This was confirmed by the infrared images, in which the foam patches appeared as hot spots. To quantify this effect, as well as the impact of rain and oil spills, and to validate the existing numerical models, the FROG 2003 (Foam, Rain, Oil spills and GPS-reflections) experiment was performed at the IRTA facilities at Poble Nou del Delta (Tarragona, Spain) to study specifically the impact of foam, rain, and oil spills on sea surface emissivity (Camps et al. 2005). Figure 12A shows the experimental set-up in which the LAURA radiometer was installed on the side of a $3 \times 7 \mathrm{~m}$
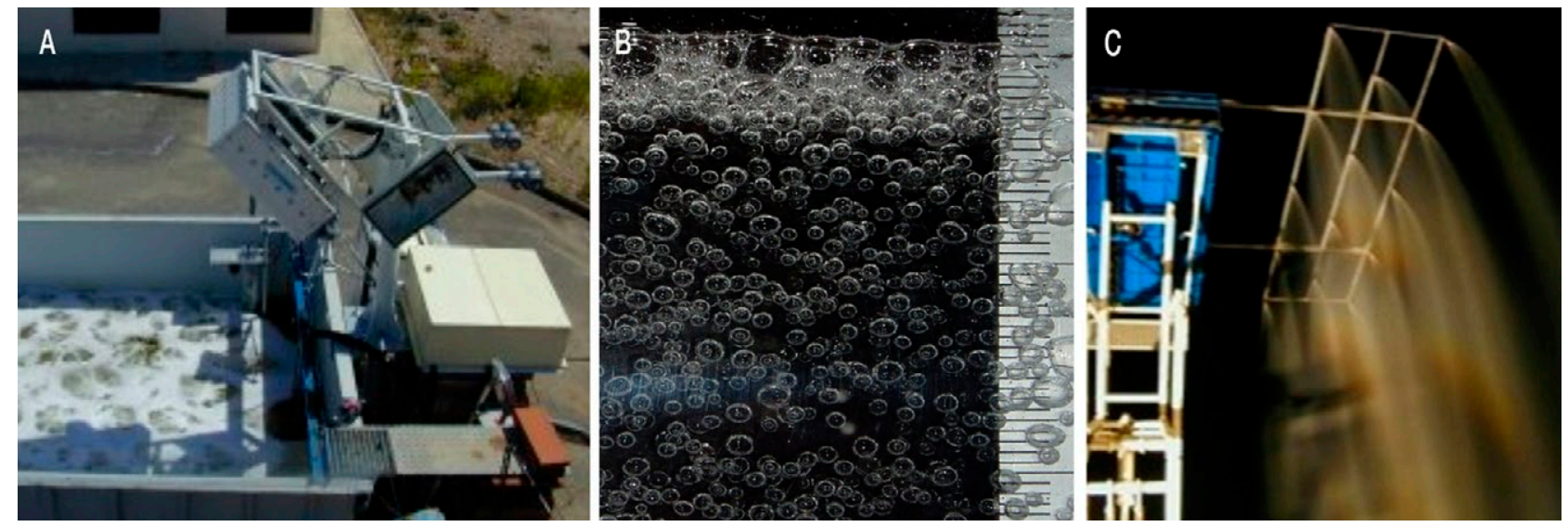

Fig. 12. - A, UPC LAURA radiometer installed on one side of a $3 \times 7 \mathrm{~m}$ salt pool with an air foam generator in FROG 2003; B, Sample image showing the foam structure; $\mathrm{C}$, rain generator over the foamy salt pool used. 

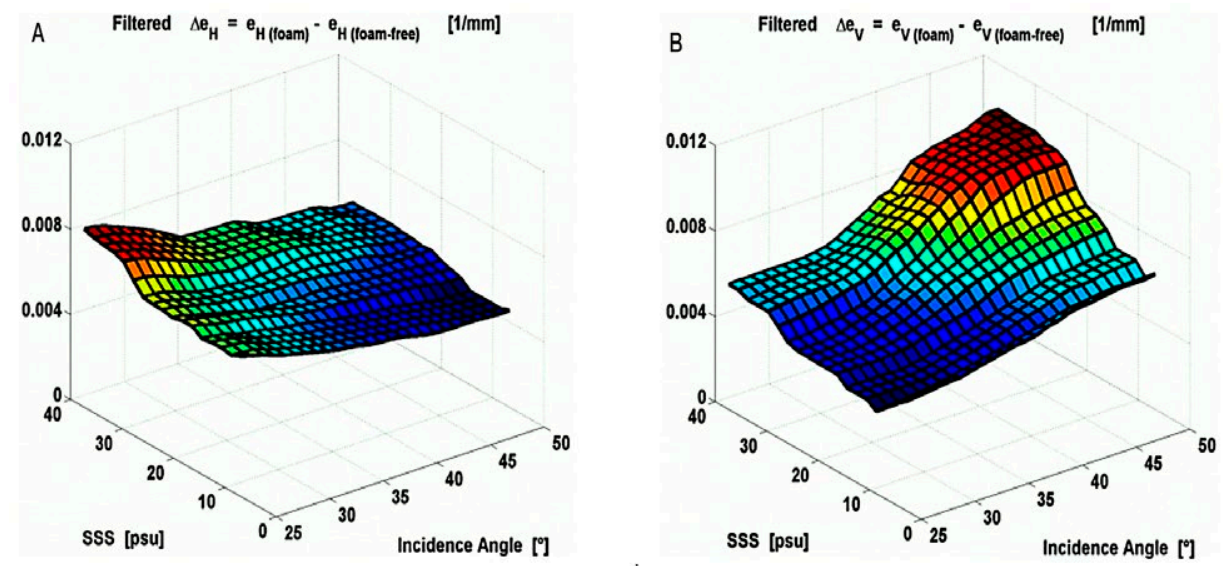

Fig. 13. - Foam emissivity increase per foam thickness unit in $\mathrm{mm}$ at $100 \%$ coverage as a function of SSS and incidence angle: A, fit at horizontal polarization; B, fit at vertical polarization (modified from Camps et al. 2005).

pool filled with a mixture of fresh and sea water. A total of 104 air diffusers distributed over the pool produced a fairly uniform foam coverage. Foam structure was analysed using video images (e.g. Fig. 12B) that were processed to infer the bubble size and distribution, and an array of conductivity sensors was used to infer the air/ water fraction as a function of depth (Camps et al. 2005). Results indicated that foam impact is not negligible and should be included in the emission model at L-band. Rain (Fig. 12C) and a thin layer of oil on the surface produce a modification of the water surface roughness that is sufficient to be detectable at L-band.

Ultimately, the impact of sea foam can be parameterized as an emissivity increment, multiplied by the foam fraction $F\left(U_{10}\right)$ :

$$
\begin{gathered}
e_{p}^{\text {total }}(\theta)=F\left(U_{10}\right) e_{p}^{\text {foam }}(\theta)+\left[1-F\left(U_{10}\right)\right] e_{p}^{\text {sea }}(\theta)= \\
=e_{p}^{\text {sea }}(\theta)+F\left(U_{10}\right) \quad e_{p}^{\text {foam }}(\theta) \\
F\left(U_{10}\right)=2.32 \cdot 10^{-6} U_{10}^{3.4988} \text {, during WISE 2000, and } \\
F\left(U_{10}\right)=0.43 \cdot 10^{-6} U_{10}^{3.6824} \text {, during WISE 2001. }
\end{gathered}
$$

Actually, $F\left(U_{10}\right)$ is also dependent on the air-sea stability and salinity, among others, and can be quite variable (see Fig. 13).

The WISE and FROG campaigns were very useful before the SMOS launch to confirm the general behaviour of the models as a function of the wind speed and foam, but once the satellite had been launched the models needed to be recomputed using the new SMOS data, and the BEC group worked hard to improve the emissivity model (Guimbard et al. 2012), which is still being used as one of the three parameterizations in the official processing chain.

\section{GNSS-R TECHNIQUES TO IMPROVE SEA SURFACE SALINITY RETRIEVALS FOR SMOS FOLLOW-ON MISSIONS}

As explained, the capability to properly correct for the sea state impact on the brightness temperature is limited; that is, the remaining uncertainty is too large to meet the scientific requirements. In this Section the main outcome of a project conducted to assess the reliance of GNSS-R (Global Navigation Satellite Systems Reflectometry) techniques to perform a better sea state correction is presented. We take advantage of the closeness in frequency of the protected passive microwave band (1400-1427 MHz) to the radio-navigation bands (L1, L2, and L5, mainly), since both emission and scattering should be affected by the same range of mechanical wavelengths (Camps et al. 2009).

The underlying concept in GNSS-R is quite simple: when the electromagnetic wave is scattered over the sea surface, the scattered signal changes its polarization (from right-hand circular to mostly left-hand circular) and arrives at the receiver mainly from the specular reflection point, determined by the shortest distance between the transmitting GPS satellite (Glonass, Beidou or Galileo) and the receiver. However, as the sea gets roughened, the scattered signals come from a wider region (known as the "glistening zone") that increases in size with increasing roughness, in a similar manner as the Sun reflecting over the sea.

In classical GNSS-R, observables are derived by cross-correlating the received scattered signal with a local replica of the pseudo-random noise signals (i.e. the open C/A code in the case of GPS) transmitted by the navigation satellites, generated at different delays and Doppler frequency shifts. Actually, the values of this two-dimensional cross-correlation are called the Delay-Doppler Map (DDM). When the sea gets rougher, the volume below the normalized DDM (peak equal to 1) down to a predetermined threshold larger than the noise level increases.

The field experiments ALBATROSS 2008 and 2009 performed in the Gran Canaria island already demonstrated that the changes in the brightness temperatures at different polarizations and incidence angles were correlated to the changes in the volume of the DDM, and that this information could be used synergetically to correct for the sea state. Actually, it was also found that the length of the tail of the waveform (the cut of the DDM for Doppler shift equal to $0 \mathrm{~Hz}$ ) at 

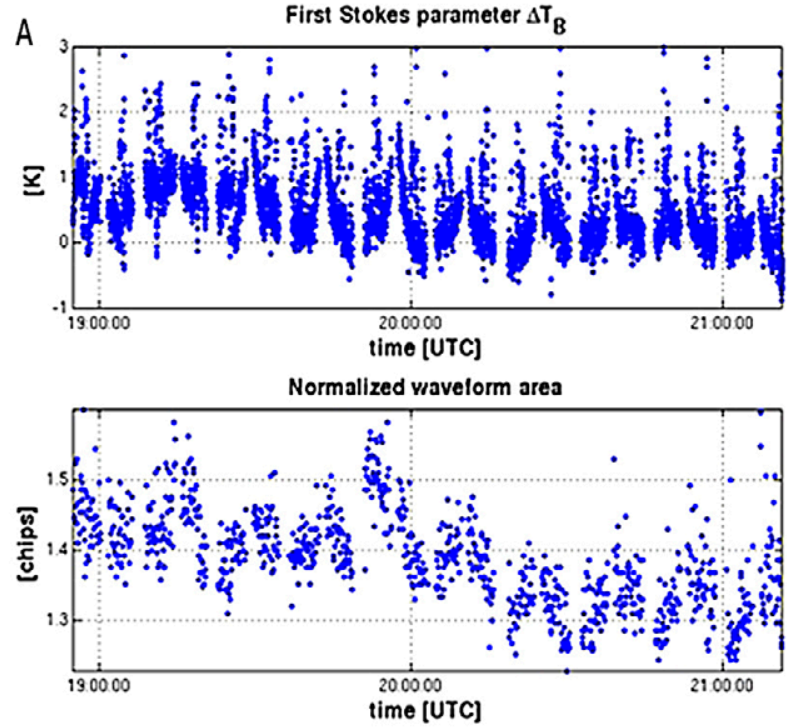

$B$

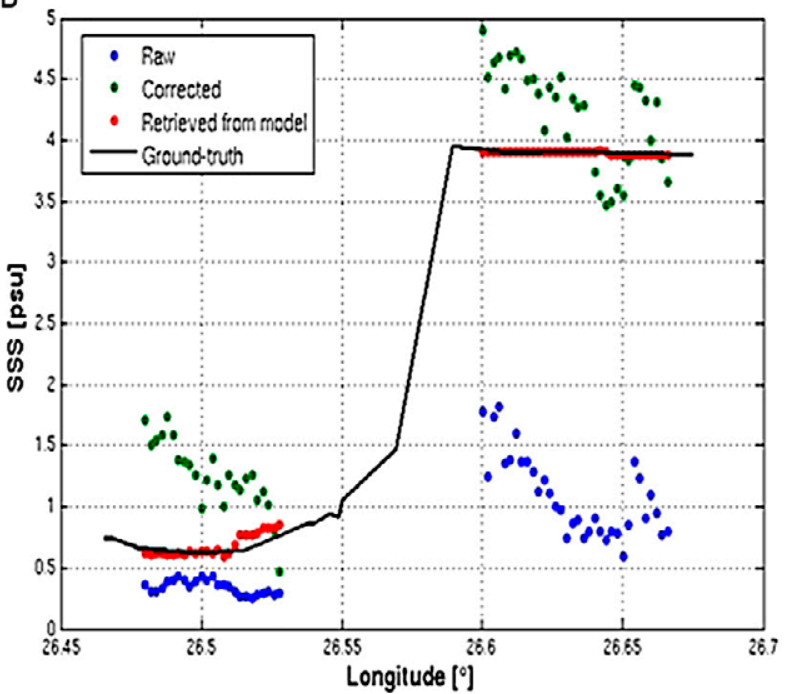

Fig. 14. - A, instantaneous variations of the first Stokes parameter (nadir-looking antenna) and area under the normalized waveform (same philosophy as explained for the DDM volume, but in the experiment GOLD-RTR was not computing DDMs); B, retrieved sea surface salinity values using GNSS-R data from GOLD-RTR from IEEC - Institute for Space Sciences/CSIC to correct for sea state (Valencia et al. 2011).

1/e was also highly correlated to the sea state (Camps et al. 2009, Marchan et al. 2009, Talone et al. 2009).

This last result was also used in the COSMOS-OS experimental data to improve the retrieval of the salinity. The experiment conditions were a number of flights perpendicular to the coast in the Gulf of Finland passing from fresh water in a lake close to the coast to (a slightly) salty water. The results are shown in Figure 14. In Figure 14A the peaks of the brightness temperature correlate well with the peaks in the normalized waveform area, suggesting a sea state correction without other auxiliary data. Figure 14B shows the improvement produced by these corrections (green dots), as compared with the retrievals using raw data.

\section{THE SMALL AIRBORNE MIRAS CAMPAIGN}

The Small airborne MIRAS (AMIRAS) was a reduced version of the MIRAS: Four elements per arm

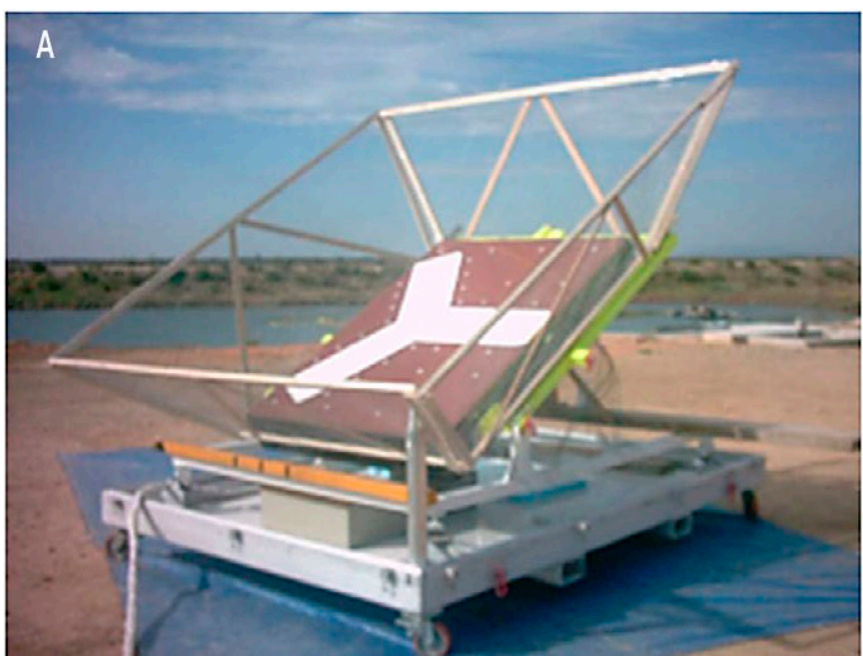

with a unit spacing of $0.875 \lambda$ and a noise injection radiometer in the centre. Most of the hardware units, including front-ends, correlators and antennas, were first-version prototypes in the framework of the SMOS project. AMIRAS had been specifically designed mechanically and thermally to fly on board the Short SC-7 Sky-van of the Helsinki University of Technology (TKK). The demonstrator was first installed in an anechoic chamber at UPC, where it underwent a number of characterization tests, including measurement of the antenna patterns.

A ground-based experiment took place with the instrument placed in the open air pointing to the cold sky (IRTA facilities, Spain). This experiment was used to measure the instrument's response to a constant target and also to make an image of the Galaxy over-pass (Martin-Neira et al. 2008). Figure 15 shows the instrument placed at the IRTA facilities and the first image of the Milky Way obtained by AMIRAS.

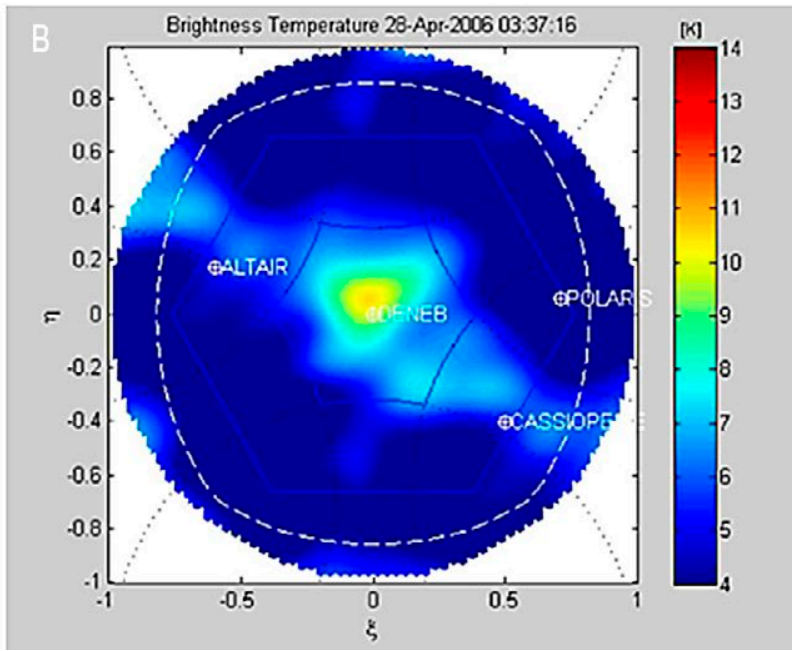

Fig. 15. - A, AMIRAS instrument on IRTA facilities for obtaining the first image of the Galaxy; B, first image of the Milky Way by AMIRAS (April 27-28, 2006). 


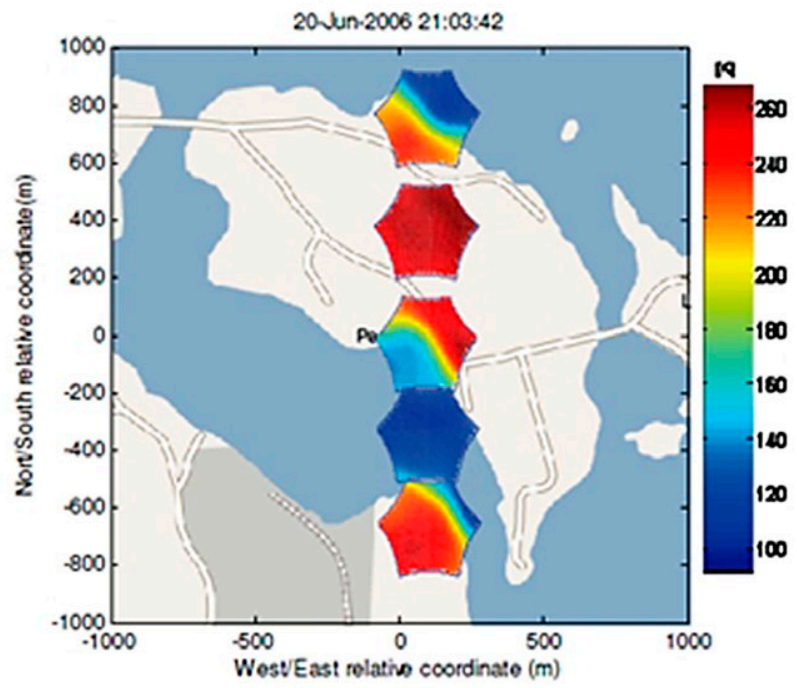

Fig. 16. - First snapshot images obtained with AMIRAS during an over-pass of an island in a lake in Finland.

Finally, the demonstrator was installed on board the TKK sky-van and was flown three times in order to acquire dual-pol images of coastlines and islands. A sequence of snapshots produced during a flight over an island was presented at IGARSS' 06 and is shown in Figure 16. It clearly reproduced the coastal geometry, qualitatively demonstrating the imaging capability of the system.

The limited spatial resolution of the AMIRAS instrument and the small number of snapshots over a single point produced a large amount of dispersion of the results, but they were extremely useful for understanding the specificities of the SMOS field of view (Corbella et al. 2008).

\section{ON-GROUND CHARACTERIZATION OF THE SMOS PAYLOAD}

The instrument was successfully assembled by EADS-CASA Espacio (Spain) and it was subjected to an extensive testing process aimed at checking the hardware and software operation as well as validating

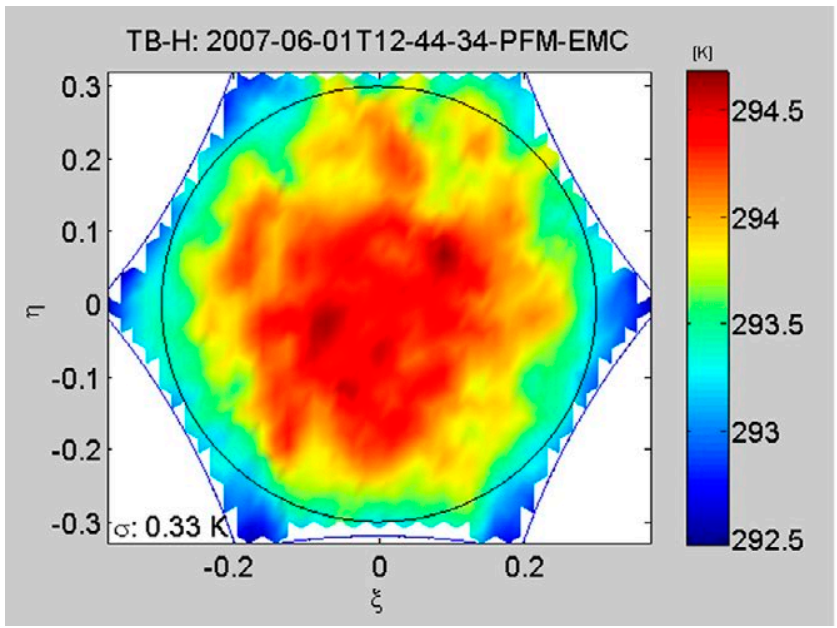

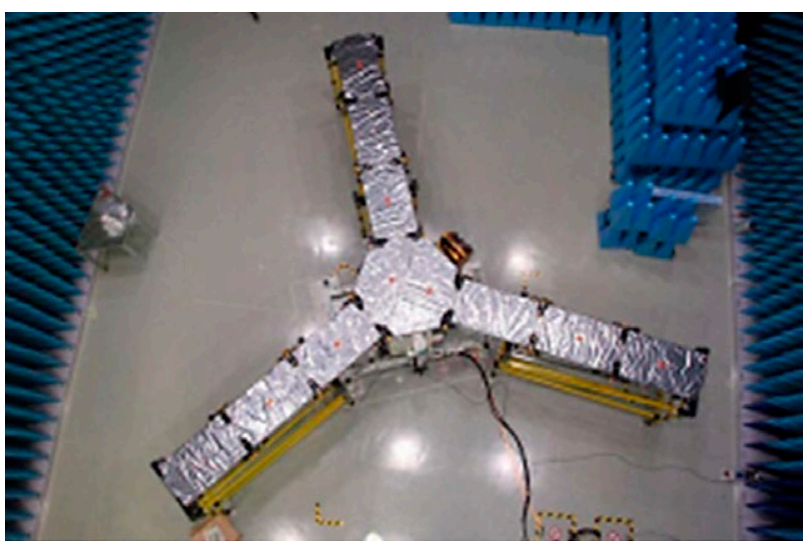

Fig 17. - SMOS payload. MIRAS fully deployed inside the Maxwell anechoic chamber at ESA-ESTEC. Courtesy of EADS-CASA Espacio.

the calibration procedures and the imaging capability. MIRAS was fully deployed inside the Maxwell anechoic chamber at ESA-ESTEC (Fig. 17) and some tests were performed on it (Fig. 18). They included the following: calibration sequence evaluation, polarization check, stability, inter-element phase retrieval, correlation offset, electromagnetic compatibility and image validation (Corbella et al. 2009).

MIRAS was successfully characterized on-ground in terms of basic operation, thermal cycling, image validation internal phase and RFI. The results showed that the instrument's performance was excellent, having all parameters according to specifications, except for an anomaly detected in the temperature dependence of the phase of correlation and a minor interference of the nominal X-band transmitter. The internal calibration concept and operation was validated, providing highly repeatable and accurate calibration parameters with low temperature sensitivity. Absolute amplitude calibration was demonstrated in the anechoic chamber using the average of all Payload Modules, PMS values, showing that the instrument could measure absolute brightness temperature with an accuracy of $0.1 \mathrm{~K}$. Images of the brightness temperature of the empty chamber showed radiometric accuracies of less than

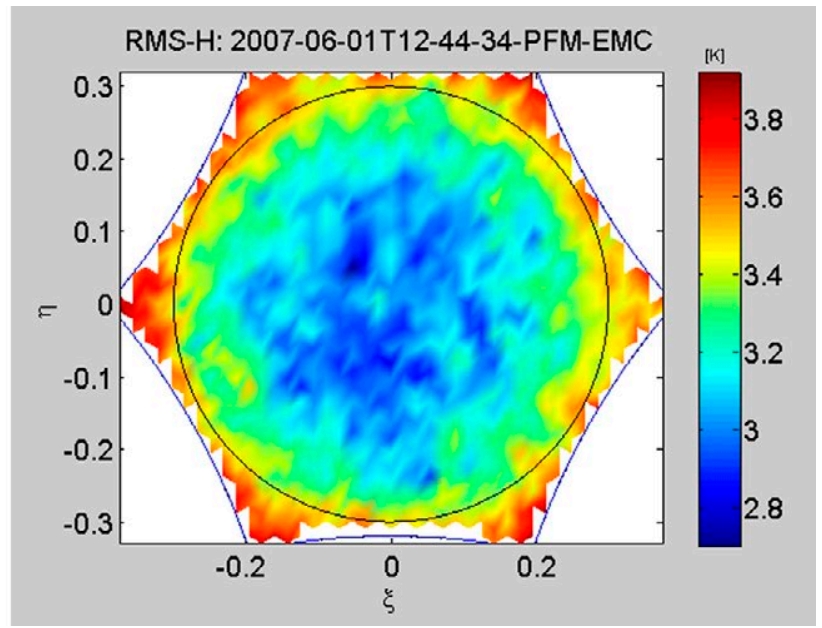

Fig. 18. - Brightness temperature (left) and radiometric sensitivity (right) of the empty chamber at H-polarization. 
half a kelvin and radiometric sensitivities according to the theoretical expectations as a function of integration time and bandwidth.

\section{BARCELONA EXPERT CENTRE AND PROCESSING CENTRE FOR LEVELS 3 AND 4}

Some of the above experimental activities and results were the embryo of the so-called empirical model (Model 3) in the SMOS L2 OS Algorithm Theoretical Baseline Document (ATBD) (SMOS ESL, 2014), which describes all the steps required to perform the retrieval of the ocean surface salinity from the calibrated and geolocated brightness temperatures (Level 1C).

Professor Font's group was one of the three Expert Support Laboratories giving advice to ESA on how to retrieve SSS (the "holy grail" of physical oceanography) from the instrument measurements from 2005.

The SMOS Barcelona Expert Centre on Radiometric Calibration and Ocean Salinity (SMOS-BEC) was created in 2007 as a joint initiative of the Spanish National Research Council (CSIC) and the Universitat Politècnica de Catalunya (UPC) to contribute to the ground segment of ESA's SMOS mission, gathering in a single entity the full spectrum of expertise required within the SMOS data processing, ranging from instrument engineers to oceanographers. The UPC's participation is made through the Passive Remote Sensing Group/Remote Sensing Lab of the Department of Signal Theory and Communications. The main CSIC actor in SMOS is the Physical and Technological Oceanography Department of the ICM, together with the Earth Observation Group of the Institute of Space Sciences (ICE). The SMOS-BEC is installed at the Institute of Marine Sciences (ICM) building, Barcelona, and Professor Font was the head of the group.

BEC's missions were to provide assessment to ESA as a Level 2 Ocean Salinity Expert Support Laboratory, to contribute to SMOS radiometric calibration and validation activities, and to develop and validate new algorithms for generating added-value products at Levels 3 and 4, helping the Spanish Processing Centre, devoted to Levels 3 and 4 (CP34), to maintain the operational generation and distribution of SSS and soil moisture (SM) products.

ESA's mandate is to process instrument data up to Level 2, (geophysical products), while Levels 3 and 4 (spatio-temporal averages and synergistic products) are produced by national agencies. Spain pushed for the CP34 (Processing Centre for Levels 3 and 4), which was initially installed at ESAC (the European Space Astronomy Centre of ESA, at Villafranca del Castillo, Spain). BEC was nominated to define and coordinate the SMOS high level products and distribution system of the CP34. INDRA was the company in charge of developing the operational software to generate the products and the dissemination tools, while the company INSA was in charge of the CP34 maintenance at ESAC. All these activities where supported by several National Plan projects led by Professor Font, called MIDAS.

In 2013, the operations of CP34 at ESAC were discontinued and BEC took over. As BEC started to generate and distribute SSS and SM products, some deep, useful changes with respect to the structure of the former CP34 were introduced: a new, easy to navigate webpage was put in place; the structure of the products was simplified and unified under the netCDF format in MF convention to better meet the needs of the scientific community; and new products and new applications were made available: the new CP34-BEC service was created. BEC's visibility increased enormously thanks to those changes, and now BEC is a reference in the processing and distribution of marine and soil moisture remote sensing products in Spain.

The data produced at BEC are served in netCDF format and are freely distributed to the scientific community by means of OPENDAP, HTTPServer and NetcdfSubset services through a THREDDS server. Maps produced by BEC can also be visualized online by means of a Web Map Service. All products are served at http://cp34-bec.cmima.csic.es/data/ available-products.

BEC creates new salinity global maps as new data reprocessing campaigns are performed by ESA and exhaustive quality control reports are made. The product description and quality reports are published at BEC-CP34 (http://cp34-bec.cmima.csic.es/doc/BECSMOS-0001-PD.pdf).

Currently, the BEC-CP34 web portal distributes the following products:

- Salinity products according to the direction of the SMOS orbit passes: ascending, descending and both products. These products are created in a variety of averaging periods: 3 days and 9 days generated every 3 days, monthly, quarterly and annually. The spatial averaging is computed by default in a regular lat-lon grid of $0.25 \times 0.25^{\circ}$. Several processes have been applied:

- Binned products are constructed by simple weighted averaging of the filtered L2 SSS values. The weighted average of SSS follows (Boutin et al. 2012).

- Optimal interpolation (OI) products: Binned products are optimally interpolated (Objective Analysis) to produce maps of higher consistency and fewer gaps as compared with the L3 binned products. The OI is performed using monthly WOA 2009 data as background field.

- L4 Fused products using singularity analysis techniques are obtained with a singularity-analysis-based fusion technique. A template variable of good quality (sea surface temperature) is used as a template to restore the multifractal structure of singularity fronts in a noisy variable (SSS in our case). Further information on the multifractal structure of ocean scalars can be found in Turiel et al. (2009).

- SMOS Mediterranean SSS products: Objectively Analysed 9-day $0.25 \times 0.25^{\circ} \mathrm{L} 3 \mathrm{SSS}$ product and Fused 1 -day $0.25 \times 0.25^{\circ} \mathrm{L} 4 \mathrm{SSS}$ product (Fig. 19).

- Land products according to ascending and descending passes

- Global Soil Moisture binned products are constructed by simple spatial averaging taking into 


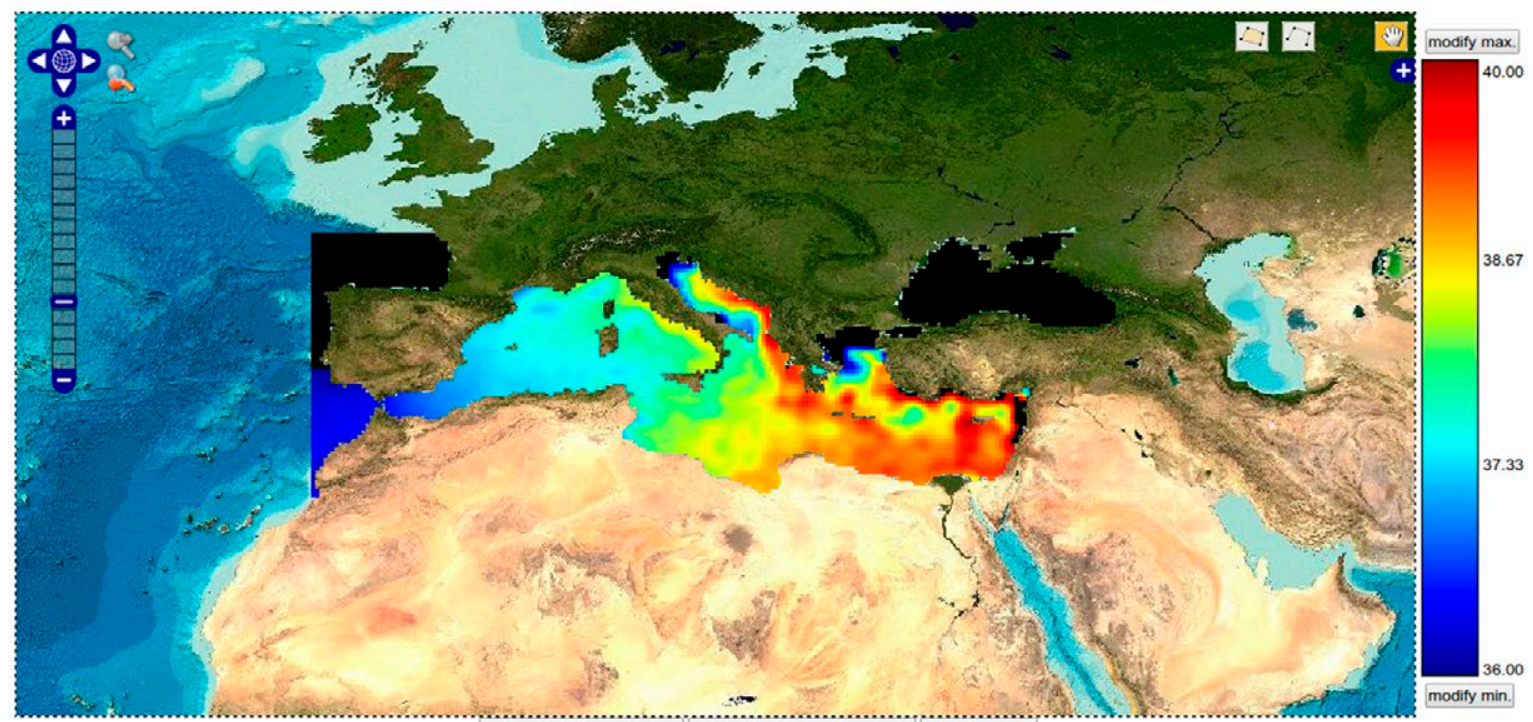

Fig. 19. - Sample experimental SMOS Mediterranean SSS products produced at the CP34 [http://cp34-bec.cmima.csic.es/ experimental-mediterranean-sss-products-now-available-at-cp34-bec/]

account only the last orbit measurements in each cell. They are operationally generated by averaging daily, 3-day, 9-day, monthly and annual data on an EASE $25 \mathrm{~km}$ grid.

- Soil Moisture Level 4 products: By combining SMOS Level 1C TBs, with Terra/Aqua MODIS land surface temperature and normalized difference vegetation index data, high resolution soil moisture maps $(1 \mathrm{~km})$ can be produced over the Iberian Peninsula with a delay of less than 12 hours. (Piles et al. 2014).

- Forest fires risk assessment and senescence: As shown in (Chaparro et al. 2015), fire ignition is more likely to occur in the northeast of the Iberian Peninsula under dry soil conditions (as seen by SMOS). Since 2012, BEC SMOS high resolution soil moisture maps in near real time are being routinely used by the Diputacio de Barcelona (DiBa) for fire risk assessment and prevention during the forest fire season.

- Other studies and products in development at BEC are:

- Sea ice concentration maps with SMOS data: At $1.4 \mathrm{GHz}$, the brightness temperature values are very different for sea and sea ice, allowing an index of ice concentration to be established. A new statistical algorithm to retrieve this index with SMOS data is being used to produce daily maps (Gabarró et al. 2015).

- SSS maps at high latitudes $\left(>50^{\circ} \mathrm{N}\right)$ have been produced. It is well known that the sensitivity of the TB to SSS decreases for cold waters (Fig. 2), but by using empirical bias correction technics, it is possible to retrieve salinities from cold waters with reasonable accuracy.

- A sea surface density product has been implemented based on the new equation of state for sea water, the thermodynamic equation of seawater, TEOS10. The product is ready to go into operation, although validation is still needed.
The maps are based in the combination of OI SSS L3 and OSTIA SST.

- TB Intercomparison between SMOS and Aquarius: Several studies on SMOS and Aquarius intercomparison have been performed for several Earth regions: Antarctica, the open ocean, dry and wet lands, the Amazon, etc. (Pablos et al. 2014).

- The ice sheet layer in Antarctica with Aquarius and SMOS data: A good agreement was observed between the brightness temperatures and the ice thickness variations over selected transects of eastern Antarctica. The presence of subglacial lakes, which are generally located at $\sim 3 \mathrm{~km}$ depth, may influence the physical temperature profile and/or the dielectric properties of the ice layers above, affecting the observed brightness temperatures (Pablos et al. 2015a, 2015b).

All these products and the research activities conducted at BEC during the last few years are broadly described in Turiel et al. (2016). The paper reviews the main scientific activities and achievements of the Barcelona Expert Centre under the direction of Jordi Font, as well as the future directions, highlighting the importance of the oceanographic applications of the mission

For his dedication to the pioneer SMOS mission, Professor Font received the Catalan National Arts Prize 2011 in the category Scientific Thought and Culture (see Fig. 20).

\section{CONCLUSIONS}

This article has summarized some of the contributions of Jordi Font, co-Principal Investigator for Ocean Salinity of the ESA SMOS Earth Explorer Mission.

Among his many direct contributions, and all those triggered by his work, we have emphasized the ICM/CSIC contributions to the field experiments WISE 2000 and 2001, and FROG 2003, which helped define the geophysical model function relating the 


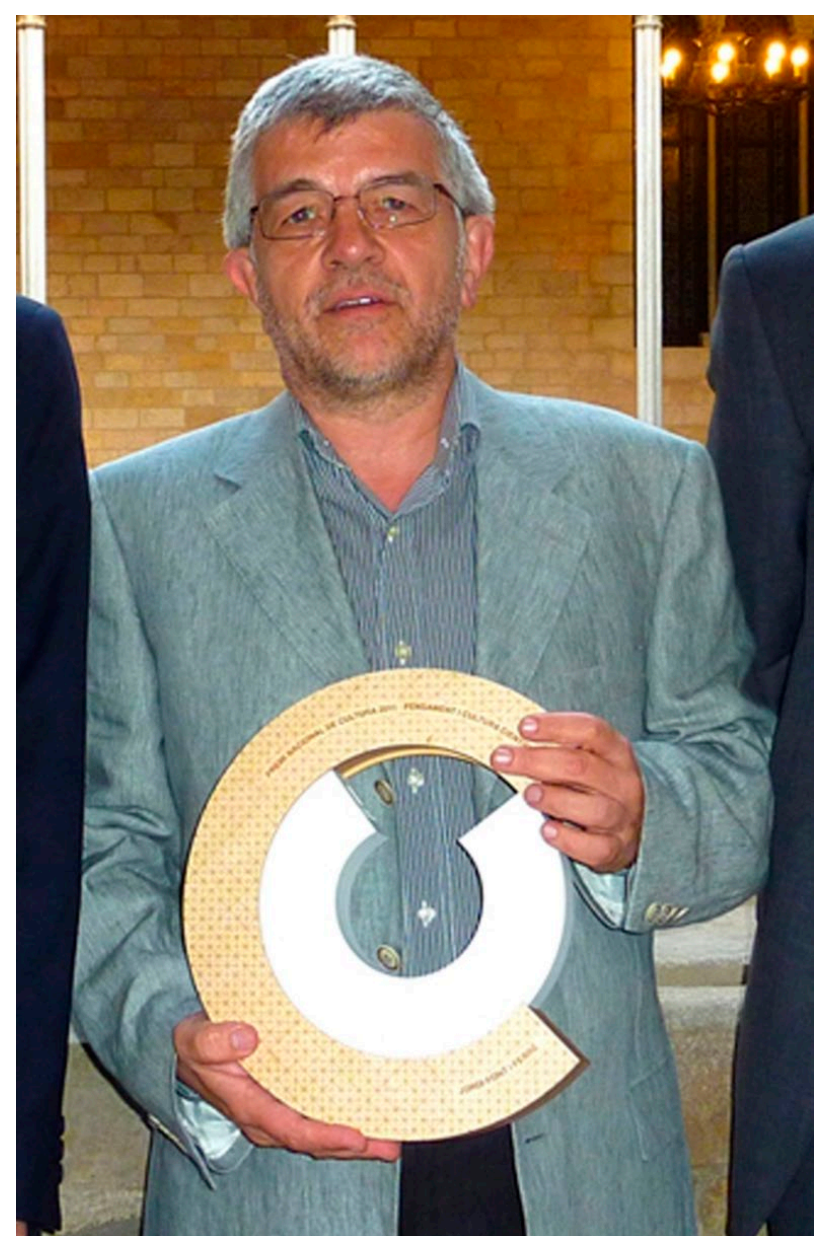

Fig. 20. - Professor Jordi Font after receiving the Catalan National Arts Award 2011

brightness temperature to the sea state. We have also stressed his efforts to establish a new ocean salinity dielectric constant. Finally, we have highlighted his drive towards the creation of the Barcelona Expert Centre, the implementation of the CP34, and the development of new products. We will miss his leadership, but his approach to oceanography will always remain.

\section{ACKNOWLEDGEMENTS}

This work has been performed under research grants TEC2005-06863-C02-01/TCM, ESP2005-06823-C05 and ESP2007-65667-C04, AYA2008-05906-C02-01/ ESP, AYA2010-22062-C05 and ESP2015-70014-C21-R, and EURYI 2004 award.

\section{REFERENCES}

Blanch S., Aguasca A. 2004. Seawater dielectric permittivity model from measurements at $\mathrm{L}$ band. Proced. IEEE Geosci. Rem. Sens. Symp. 2: 1362-1365. http://dx.doi.org/10.1109/igarss.2004.1368671

Boutin J., Martin N., Yin Y., et al. 2012. First assessment of SMOS data over open ocean: Part II-sea surface salinity. IEEE Trans. Geosci. Rem. Sens. 50 : 1662-1675. http://dx.doi.org/10.1109/TGRS.2012.2184546

Camps A., Font J., Etcheto J., et al. 2002. L-band sea surface emissivity radiometric observations under high winds: Preliminary results of the Wind and Salinity Experiment WISE-2001. Proceed. IEEE Geosci. Rem. Sens. Symp. 3: 1367-1369. http://dx.doi.org/10.1109/igarss.2002.1026118

Camps A., Font J., Vall-1lossera M., et al. 2004. The WISE 2000 and 2001 field experiments in support of the SMOS mission: sea surface L-band brightness temperature observations and their application to sea surface salinity retrieval. IEEE Trans. Geosci. Rem. Sens. 42(4): 804-823. http://dx.doi.org/10.1109/tgrs.2003.819444

Camps A., Vall-1lossera M., Villarino R., et al. 2005. The emissivity of foam-covered water surface at L-band: theoretical modeling and experimental results from the FROG 2003 field experiment. IEEE Trans. Geosci. Rem. Sens. 43(5): 925-937. http://dx.doi.org/10.1109/TGRS.2004.839651

Camps A., Bosch-Lluis X., Ramos-Perez I., et al. 2009. New Passive Instruments Developed for Ocean Monitoring at the Remote Sensing Lab-Universitat Politècnica de Catalunya. Sensors 9: 10171-10189. http://dx doi.org/10.3390/s91210171

Chaparro D., Vall-llossera M., Piles M., and the SMOS-BEC Team. 2015. Remotely sensed soil moisture and forestry applications. SMOS Science Workshop ESA-ESAC, Villafranca del Castillo (Madrid), Spain

Corbella I., Torres F., Duffo N., et al. 2008 Brightness Temperature retrievals from the Small Airborne MIRAS, IGARSS'08, Massachusetts, USA.

Corbella I, Torres F., Duffo N., et al. 2009. On-Ground Characterization of the SMOS Payload, 2009. Trans. Geosci. Rem. Sens. 47: 3123-3132. http://dx.doi.org/10.1109/TGRS.2009.2016333

Ellison W., Balana A., Delbos G., et al. 1998. New Permittivity Measurements of Sea Water. Radio Sci. 33(3): 639-648. http://dx.doi.org/10.1029/97RS02223

Emelianov M., Font J., Julià A., et al. 2003. Sea surface fields at Casablanca site (NW Mediterranean) during the EuroSTARRS campaign. In: Proceedings of SMOS Campaigns Workshop, ESA SP. 525: 73-80.

Font J., Gabarró C., Julià A., et al. 2003. Oceanographic conditions during the Wind and Salinity Experiment 2000 and 2001, NW Mediterranean Sea. In: Proceedings of SMOS Campaigns Workshop, ESA SP. 525: 51-59.

Gabarró C. 2004. Study of salinity retrieval errors for the SMOS mission. $\mathrm{PhD}$ thesis, Tech. Univ. Catalonia.

Gabarró C., Font J., Camps A., et al. 2003. Retrieved Sea Surface Salinity and Wind Speed from L-Band measurements for WISE and EuroSTARRS campaigns. In: Proceedings of SMOS Campaigns Workshop, ESA SP. 525: 163-171.

Gabarró C., Font J., Camps A., et al. 2004. A new empirical model of sea surface microwave emissivity for salinity remote sensing. Geophys. Res. Lett. 31: L01309. http://dx.doi.org/10.1029/2003GL018964

Gabarró C., Pla Q., Elosegui P., et al. 2015. Investigating SMOS data for sea ice concentration determination. SMOS Science Workshop, ESAC- Madrid, Spain.

Guimbard S., Gourrion J., Portabella M., et al. 2012. SMOS SemiEmpirical Ocean Forward Model Adjustment. IEEE Trans. Geosci. Rem. Sens. 50: 1676-1687. http://dx.doi.org/10.1109/TGRS.2012.2188410

Hollinger J.P. 1971. Passive Microwave Measurements of Sea Surface Roughness. IEEE Trans. Geosci. Electronics, GE-9(3): 165-169. http://dx.doi.org/10.1109/TGE.1971.271489

Klein L.A., Swift C.T. 1977. An improved model for the dielectric constant of sea water at microwave frequencies. IEEE Trans. Anten. Propag. AP 25: 104-111. http://dx.doi.org/10.1109/TAP.1977.1141539

LeVine D.M., Zaitzeff J.B., D'Sa E.J., et al. 2000. Sea surface salinity: toward an operational remote-sensing system. Satellites, oceanography and society. Elsevier Oceanography Series 63: 321-335.

Marchan J.F., Camps A., Rodríguez N., et al. 2009. An Efficient Algorithm to the Simulation of Delay-Doppler Maps of Reflected Global Navigation Satellite System Signals. IEEE Trans. Geosci. Rem. Sens. 47: 2733-2740. http://dx.doi.org/10.1109/TGRS.2009.2014465

Martin-Neira M., Cabeza I., Pérez C., et al. 2008. AMIRAS - an airborne MIRAS demonstrator. IEEE Trans. Geosci. Rem. Sens. 46(3): 705-716.

http://dx.doi.org/10.1109/TGRS.2008.916266

Miller J., Goodberlet M.A., Zaitzeff J. 1996. Airborne salinity map- 
per makes debut in coastal zone. EOS Trans. AGU 79: 173-177. http://dx.doi.org/10.1029/98EO00126

Pablos M., Piles M., González-Gambau V., et al. 2014. SMOS and Aquarius Radiometers: Inter-Comparison over Selected Targets, IEEE J-STARS 7(9): 3833-3844. http://dx.doi.org/10.1109/jstars.2014.2321455

Pablos M., Piles M. González-Gambau V., et al. 2015a. Ice Thickness Effects on Aquarius Brightness Temperatures over Antarctica. J Geophys Res C 120(4): 2856-2868. http://dx.doi.org/10.1002/2014JC010151

Pablos M., Piles M., González-Gambau V., et al. 2015b. Influence of Ice Thickness on SMOS and Aquarius Brightness Temperatures over Antarctica. IEEE IGARSS 2015, 26-31 July 2015, Milan (Italy) pp. 5178-5181. http://dx.doi.org/10.1109/igarss.2015.7327000

Piles M., Sánchez N., Vall-llossera M., et al. 2014. A Downscaling Approach for SMOS Land Observations: Evaluation of HighResolution Soil Moisture Maps Over the Iberian Peninsula IEEE J-STARS 7(9): 3845-3857. http://dx.doi.org/10.1109/jstars.2014.2325398

Ruf C.S., Swift C.T., Tanner A.B. et al. 1998. Interferometric synthetic aperture microwave radiometry for the remote sensing of the Earth. IEEE Trans. Geosci. Rem. Sens. 26: 597-611. http://dx.doi.org/10.1109/36.7685

Silvestrin P., Berger M., Kerr Y., et al. 2001. ESA's second earth explorer opportunity mission: The soil moisture and ocean salinity mission - SMOS. IEEE Geosci. Rem. Sens. Newslett. 118: 11-14.

SMOS Salinity Expert Support Laboratories. 2014. SMOS
L2 OS Algorithm Theoretical Baseline Document, ref SO-TN-ARG-GS-0007.

https://earth.esa.int/web/guest/-/data-processors-7632

Swift C.T. 1980. Passive microwave remote sensing of the ocean - a review. Boundary - Layer Meteorology. 18: 25-54. http://dx.doi.org/10.1007/BF00117909

Swift C.T., McIntosh R.E. 1983. Considerations for microwave remote sensing of ocean-surface salinity. IEEE Trans. Geosci. Elec. 21: 480-491. http://dx.doi.org/10.1109/tgrs.1983.350511

Talone M., Camps A., Marchan-Hernandez J.F., et al. 2009. Preliminary Results of the Advanced LBand Transmission and Reflection Observation of the Sea Surface (ALBATROSS) Campaign: Preparing the SMOS Calibration and Validation Activities. Proc. IEEE Int. Geosci. and Rem. Sens. Symp., Cape Town, South Africa.

Turiel A., Nieves V., Garcia-Ladona E., et al. 2009. The multifractal structure of satellite sea surface temperature maps can be used to obtain global maps of streamlines. Ocean Sci. 5(4): 447-460. http://dx.doi.org/10.5194/os-5-447-2009

Turiel A., Piles M., González-Gambau V., et al. 2016. 2000 days of SMOS at the Barcelona Expert Centre: a tribute to the work of Jordi Font. Sci. Mar. 80S1: 173-193. http://dx.doi.org/10.3989/scimar.04291.15A

Valencia E., Camps A., Rodriguez-Alvarez N., et al. 2011. Improving the accuracy of sea surface salinity retrieval using GNSS-R data to correct the sea state effect. Radio Sci. 46: RSOC02. http://dx.doi.org/10.1029/2011RS004688 